\title{
The Public Finance Management Act as a Reform Measure to Capacitate Public Officials
}

\section{J Fourie}

School for Public Management and Administration, University of Pretoria

\section{ABSTRACT}

The urgent need to develop South Africa's human resources in the public service has been conceptualized in many policy documents. The underlying objective of efforts to strengthen the human resources in the public sector, is the delivery of effective services to the people of South Africa. In line with the White Paper on the Transformation of the Public Service, 1995, the effective mobilization, development and utilization of human resources are stressed as important factors in the transformation of the public service because of their contribution to individual and institutional capacity to ensure effective governance. Financial resources are important in order to develop and sustain the skills of the public servants; however, there is a tendency to cut the budget for human resource development programmes. Alternative methods should be developed to obtain additional sources of income.

JEL H0O, H70

\section{INTRODUCTION}

The training programmes for public servants inherited from the former regime, lacked a proper strategic, needs-based and outcomes-based focus. In order to address the shortcomings in terms of training in the public service, a number of policy documents have been developed, aimed at addressing human resource development of the public service. The policy documents underpin a strategy that coordinates the broader process of transformation and institution building, with human resource development in the public service and emphasize that education and training should be strategically planned and effectively resourced. With reference to financial resources, the White Paper on Public Service Training and Education (WPPSTE), determines that a specific percentage of the annual budget of public service departments be allocated towards training and development of human resources. However, this percentage is not sufficient to address the backlog that has developed over the years. The situation is worsened by the cut backs on departmental budgets which impact directly on training budgets. 
Altemative funding is required to finance training programmes. The Public Finance Management Act, 1999, creates an opportunity to generate additional sources of income for public service departments.

\section{STATUS OF HUMAN RESOURCE DEVELOPMENT IN THE SOUTH AFRICAN PUBLIC SERVICE}

The Human Resources Development (HRD) programme as inherited from the former regime was fragmented and poorly coordinated. Human resource development was characterized mainly by a lack of strategic, needs-based and outcomes-based focus, as well as by the inappropriate nature of the training and education provided by the various in-service and external providers (White Paper on Public Service Training and Education, 1998).

Given the urgent need to overcome some of the problems mentioned above and to build individual and institutional capacity for the new public service, the White Paper on the Transformation of the Public Service (24 November 1995) regards the development of South Africa's human resources as one of the five key programmes of the Reconstruction and Development Programme (RDP) (September 1994). This can be ascribed to the fact that the development of the country's human resources is central to the process of obtaining the strategic objectives set out in the RDP.

In order to have a clear understanding of the need for human resource management, the Table indicates the distribution of race and skills the public service according to race and skills level.

Table 1 shows clearly that there is a need for human resource development, allowing public servants with lower skills levels to be promoted from one level to the next, more highly skilled level. As a result, a strategic framework for effective human resource development has been developed. 
Table 1 Distribution of the public service according to race and skills level, 1999

\begin{tabular}{|l|c|c|c|c|}
\hline \multirow{2}{*}{} & African & Asian & Coloured & White \\
\cline { 2 - 5 } & \multicolumn{4}{|c|}{ Percentage } \\
\hline Lower skilled & 88 & 2 & 9 & 2 \\
\hline Skilled & 74 & 4 & 9 & 13 \\
\hline Highly skilled production & 66 & 4 & 9 & 21 \\
\hline Highly skilled supervision & 42 & 6 & 6 & 47 \\
\hline Management & 28 & 5 & 6 & 61 \\
\hline Senior Management & 47 & 7 & 9 & 37 \\
\hline Proportion of population & $\mathbf{7 7}$ & $\mathbf{3}$ & $\mathbf{9}$ & $\mathbf{1 1}$ \\
\hline
\end{tabular}

Source: Department of Public Service and Administration, 1999/2000: 13

The following are some of the elements of the strategic framework (Presidential Review Commission, 1998: 146);

(i) human resources should be strategically linked to the broader process of transformation, institution building and human resources development in the public service;

(ii) adherence to the National Qualifications Framework (NQF) and the South African Qualifications Authority (SAQA) frameworks, including the proposals regarding the Department of Labour's new Skills Development Strategy;

(iii) education and training should be strategically planned and effectively resourced;

(iv) the elevation of the importance and status of training and trainers; and

(v) human resource development should be effectively organized, coordinated and accredited in ways that promote and enhance quality, accountability, transparency and cost-effectiveness.

In terms of the White Paper on Public Service Training and Education, the main objective is to enable departments to design and implement training programmes and education that are linked to the strategic priorities of the departments. Therefore, it is required that certain key aspects and organizational structures be formalized in order to provide training and education in a meaningful and effective manner (Presidential Review Commission, 1998: 147).

It is envisaged that the White Paper on Public Service Training and Education will contribute to the materialization of the comprehensive HRD strategy and programme, which White Paper provides the following: 
(i) The Government has adopted a policy whereby centralized norms and standards are set, but in a decentralized manner with both state and nonstate providers, in a competitive framework. It is therefore argued that the delivery of training and education programmes will combine creativity and flexibility without undermining the need to build a unified public service with a common culture and value system.

(ii) In addition to the centralized norms, the White Paper on Public Service Training and Education provides for the review of statutory and other regulatory instruments and frameworks in order to facilitate efficiency and accountability in HRD in the public service. This means that individual departments will be able to integrate human resource development planning and implementation with new approaches to the overall management of resources. This process is relevant, as it will allow individual departments to specify and implement linkages between skills development, grading and acceleration in the areas of critical skills shortages.

(iii) The White Paper on Public Service Training and Education specifies a formula prescribing a percentage of departments' payroll that should be allocated to training and education. In this regard, it is stated in the Budget Review (2000; 50) that expenditure on education and training has to be at least 0.5 per cent of the payroll in $2000 / 01$ and 1 per cent in 2001/02 and beyond (See Table 2). This means that departments have to reflect the strategic importance of training and development in the allocation of resources, taking into consideration the Medium Term Expenditure Framework. It should be noted that the budget for HRD is small compared to international standards. In this regard the Presidential Review Commission's Report (1998: 150) states that in the departments surveyed, the ratio of HRD budgets to the overall departmental budget ranged from 0.02 per cent (National Department of Housing) to 0.3 per cent (Department of Home Affairs).

Table 2 Expenditure on skills development, 1999/00-2002/03

\begin{tabular}{|l|c|c|c|c|}
\hline $\begin{array}{l}\text { Government Training } \\
\text { expenditure (R million) }\end{array}$ & $1999 / 00$ & $2000 / 01$ & $2001 / 02$ & $2002 / 03$ \\
\hline National departments & 427 & 464 & 287 & 300 \\
\hline Provinces (9) & - & 335 & 704 & 740 \\
\hline
\end{tabular}

Source: South Africa, Department of Finance, Budget Review, 2000: 50

Table 2 clearly shows that the expenditure on skills development is not sufficient to support an effective training strategy. National Departments employ 306312 public officials (Department of Public Service and 
Administration, 1999/2000: 12). The amount available for training per official is on average R1 394 per official for the financial year 2000/01. For the year $2001 / 02$ this average declines to R936.95 per official. This allocation is a mere drop compared to what is required to meet training priorities.

The training budget for provincial departments, 759689 officials (Department of Public Service and Administration, 1999/2000: 12) was a mere R440 per official for the 2000/2001 financial year. For the financial year 2001/2 the amount available per official is R926.69 and for the 2002/03 financial year the amount is increased to R974.08 per official. One can assume that the increase in the expenditure on skills development especially on provincial level, is to strengthen the provincial services that are actively responsible for the provision the social services such as health, welfare and education. The allocation for the promotion of HRD on provincial level is inadequate to address the provincial development needs.

With the current HRD in the South African public service in mind and in particular the three issues regarding the development of the HRD strategies and programmes, it is necessary to focus briefly on the institutions responsible for training and education in the public service.

\section{INSTITUTIONS RESPONSIBLE FOR PUBLIC SERVICE TRAINING}

A number of institutions are responsible for the facilitation and enhancement of HRD in the public service, the roles of which will be briefly highlighted.

\subsection{Public Sector Education and Training Authority (PSETA)}

The PSETA has been established by the Government to play a part in the design, delivery and evaluation of public service training and development. The functions of the PSETA are broad and varied, therefore the establishment of sectoral education and training authorities (SETAs). These authorities play an important role to co-ordinate professional and vocational education and training throughout the respective economic sectors (White Paper on Public Service Training and Education, 1998).

In principle the Government should provide seed money for training in accordance with the identified training needs. Thereafter, it must be the responsibility of each SETA to find ways and means to generate income to sustain its existence. This may take the form of charging trainees a nominal fee to break even with the cost of training. Simultaneously, this exercise will 
generate income to ensure that the institution continues with its mandate of training public servants. Furthermore, the pressure of finding resources to sustain itself will compel the institution to deliver high quality training programmes.

\subsection{Association of Accredited Training and Education Providers (AATEP)}

The Association of Accredited Training and Education Providers was established by Government to promote planning and coordination of the work of the South African Management Development Institute (SAMDI), provincial training bodies and external training providers. The Association also has the function of encouraging and facilitating peer review, mutual support and the development of the teaching and learning profession amongst accredited training and education providers. It should be noted that membership of this Association is voluntary (White Paper on Public Service Training and Education, 1998: 56 and 58).

In order to allow the Association to continue its function of coordination and planning, its members must pay annual subscription fees. Since education and training providers vary in size in terms of student enrolment, members' fees are determined according to student numbers. Furthermore, to strengthen its financial base, this Association may provide services to other institutions and thereby generate additional income.

\subsection{South African Management Development Institute}

The South African Management Development Institute (SAMDI) operates as a separate entity under the political authority of the Minister for Public Service and Administration. SAMDI is responsible for the provision of public service education and training to the different government departments. To ensure selfsufficiency, SAMDI should recover its direct training expenses from departments and other users. The mandate of SAMDI includes as main objective, targeting of resources, provision, publication and monitoring of plans and targets for training of the different government departments. Furthermore, SAMDI focuses its attention on the priority area - public management training (Department of Finance, 2000: 73).

In order to provide the training SAMDI has a staff component of 63 officials (SAMDI, Annual Report 1999/2000: 9) and a total budget of R13.9 million for the financial year 1999/2000. In addition to the budget allocated by Parliament, SAMDI received R26.7 million from the European Union during the financial year 1999/2000 as part of the Public Service Management Development 
Programme. By the end of February 2000 only 65 per cent of the total budget of R40.6 million was spent (SAMDI, 1999/2000: 12). Between March 1999 and March 2000, SAMDI managed to train 9500 public servants (Fraser-Moleketi, 2000). Percentage wise, this means that only 0.89 per cent public servants out of I 065999 million public servants have been trained at a total cost of R2 789 per official.

\subsection{Public service institutions}

Government departments offer in-service training programmes. These in-service training programmes take various forms, including training of trainers and mentorship programmes. This form of training focuses on the improvement in the functioning of a department. Furthermore, departments utilize the formal education courses at educational institutions such as universities and technikons. This form of training and development is supported by the individual department's bursary arrangements managed by the human resources or personnel component of the specific department.

\subsection{Institutions of higher learning}

The tertiary institutions (there are 22 Universities and 15 Technikons) will make important contributions in all sectors of education and training. Tertiary institutions fulfill a pivotal role in the revision of more long-term, formative training and learning programmes. Such programmes provide continuous, all round skills which normally is possible or feasible within short-term training programmes (White Paper on Public Service Training and Education, 1998: 66$67 \mathrm{cf}$. also Department of Finance, 2000: 108).

\subsection{Community-based and non-government organizations}

Community-based and non-government organizations possess knowledge, practical experience and expertise that should be utilized directly and continuously as a resource base for public service training. With the assistance of these organizations, public servants will be able to expand their knowledge regarding the increasingly diverse and complex needs of local communities. Public servants may also gain knowledge regarding negotiation and consulting skills, participatory learning and teaching, as well as human rights and civic consciousness.

As mentioned earlier, extemal institutions are important in the development of human resources in the public service. This implies that, apart from the national institutions, Government will also from time to time, and according to need, seek to encourage cooperation between training and development organizations 
inside South Africa and those outside the country (White Paper on the Transformation of the Public Service, 1995: 67).

The institutions mentioned above will have both a direct and indirect influence on budgets of public institutions. It should also be mentioned that there is a failure in general on the side of government departments to make adequate provision in terms of financial and human resources for training within their organizational structures. As indicated in Table 2 and the analysis of the skills development budget, a relatively small amount of the total budget is devoted to training and education in the public service. Therefore, alternative ways and means of generating additional financial resources should be found to fund HRD programmes.

\section{ALTERNATIVES FOR GENERATING TRAINING FUNDS}

As mentioned earlier, education and training can be regarded as essential components in the development of the skills of the public service workforce. It also promotes economic development, reduces unemployment and enhances social development. Despite Government's intentions to provide training to its employees, it is often faced with budgetary constraints and it should be mentioned that the current primary budget deficit amounts to R19.7 billion (Department of Finance, 2000: 9). In the process of balancing the budget of a department, it is customary to cut the budget of the training division. Therefore, the training division of a department should find alternative sources to generate additional income. In this regard, the Public Finance Management Act, 1999 (Act 1 of 1999), could play an important role as the Act adopts an approach to financial management which focuses on outcomes and responsibilities instead of the rule-driven approach of the out-dated and old exchequer acts.

\subsection{Regulatory framework}

The introduction of new legislation and regulations provided a significant step towards the generation of additional resources. In this regard the new Public Finance Management Act of 1999 as amended and implemented on 1 April 2000 , represents one of the most important reform measures undertaken by Government to improve financial management in the public sector and as a mechanism to improve the generation of additional income. Previous financial legislation, e.g. the Exchequer Act, 1975 (Act 66 of 1975) did not allow for autonomous financial creativity. The Public Finance Management Act of 1999 as amended assigns greater responsibilities and allows greater powers to accounting officers, and provides the means by which the latter can be held accountable for exercising their managerial prerogatives. The Public Finance 
Management Act of 1999 is designed to enable managers to manage more effectively and to empower them to reallocate resources. The Treasury Regulations for Departments and Constitutional Institutions as issued in terms of the Public Finance Management Act of 1999 play an important supportive role in the effort towards effective and efficient financial management. Treasury Regulation 7.1 could be mentioned as an example. This regulation deals with revenue management more specifically, with the identification, collection, recording and safeguarding of all revenues for which an institution is responsible. The old Treasury Instructions were strictly procedural and did not allow the accounting officer to manage revenue management in a creative and effective manner. The new regulations provide room for innovative and creative revenue management. Treasury Regulation 7.2 states that the accounting officer of an institution must manage the revenue collected efficiently and effectively. Therefore, appropriate processes that would allow for the identification, collection, safeguarding, recording and reconciliation of information regarding revenue (also revenue obtained for the purposes of training) must be developed and implemented.

\subsection{Business enterprises}

Training divisions in the various departments need to determine their actual needs and develop proposals, which should then be submitted to local businesses for support. There are various ways in which the business sector can assist training divisions of departments. Businesses can contribute by donating funds to a particular institution or it can adopt a training project. For example, the management training programmes of the South African Police Service are supported financially by Business Against Crime. In 2000, Business Against Crime supported the delivery of the Police Station Management Programme offered by the Joint Universities Public Management Education Trust, for 26 participants with a budget of R260000 (Purkis, 2000). As an incentive, the financial contributions to such programmes are within the prescribed taxdeductible limits (Department of Finance, 2000: 82-84).

\subsection{Creation of a non-profit organization}

The purpose of a Section 21 company established in terms of the Non-profit Organizations Act (Act 71 of 1997) is to operate loan and bursary schemes for public servants who want to pursue their formal education, but lack the financial means. Funds for bursaries and loans can be raised from local and international donors. The Umsobomvu Fund (R855 million), for instance, invests in young people to develop skills and knowledge (Department of Finance, 2000: 46). 
In the case of loans, a system to enforce repayment should be established. The repayment of loans may present some practical problems as in the case of tertiary institutions Departments should take note of these.

\subsection{Joint-venture projects}

Joint-venture projects are currently an untapped source of funding for training programmes. Institutions in need of particular skills that public servants may have, cannot in all circumstances meet the needs on their own. Arrangements could be made between the training division of a department and those companies who require the skills transfer. A training fee should be payable to the training division of the department to enable it to provide the required training. A practical example of this is the training provided by staff at academic hospitals that possess particular skills to staff at private hospitals who require those skills. In the past, this training was done free of charge whilst the academic hospital carried the cost of the staff member not involved with their core responsibility for that particular day (Hospital Strategy Report, Module $3.1,1996)$.

\subsection{Creation of partnerships}

Government is implementing a strategic framework for delivering some public services through innovative public-private partnerships. This could improve service delivery to the public whilst at the same time transferring the risks to private contractors who are sometimes in a better position to manage the delivery of services. Innovative projects in the field of training will benefit from this arrangement. A contractual agreement can generate additional income for the training divisions by way of annual registration fees of the private companies wishing to be included in the training division's data base. This implies that a private sector company will have access to information regarding the offering of training programmes. It also allows the public sector the opportunity to regulate and monitor training standards and performances by training institutions.

\subsection{Donations and fund raising}

Previous legislation through the Exchequer Act (Act 66 of 1975), and the previous Treasury Instructions did not allow for government departments, in particular a training division, to raise funds other than the allocated budget for training programmes. The new legislative framework allows for creativity and innovation in the management of public funds and thus allows for fund raising (Van der Linde, 2000). This means that the training division can now actively be involved in the raising of funds through partnerships, donor organizations, 
and private sector companies. An official may be contracted to actively raise funds. However, an incentive scheme should be in place to motivate the assigned official to raise funds effectively.

\subsection{Protecting of intellectual copyright}

Training officials are required to develop training material to meet the specific needs of the public service department. In some cases, the material is a sought after commodity as it could enhance the skills and experience of persons in the industry. Training manuals are seen as public goods which industry uses and often profits in doing so. To ensure that the development cost is covered, the training material can be made available to other institutions at.a fee sufficient to cover these costs.

\subsection{Providing of equipment and facilities to other users}

Training equipment and facilities should be utilized optimally and training divisions can make the equipment and facilities available to other institutions at a market-related charge. This will not only be a source of income but also ensure proper utilization of the equipment or facilities. Funds generated in this way can be used to replace old and outdated training equipment, rather than having to depend on a departmental budget, which budget is awarded low priority in the budgeting process.

In conclusion, Governments are faced with budget deficits and innovative and creative ways should be launched to find additional sources of income. To achieve this, training divisions should hold strategic sessions to identify not only their weak and strong points, but also to identify the opportunities that are available to generate additional income. This will hopefully ensure a commitment from the personnel of the training division who will then pursue these opportunities. Also, there should be a clear departmental policy that the income thus generated will be allocated to the training division. In the absence of such a policy, the danger exists that the head of the department may allocate the additional funds generated by the training division to a different project or division in the department.

\section{REQUIREMENTS FOR EFFECTIVE FINANCIAL MANAGEMENT}

To ensure that the training division operates efficiently, particular requirements for financial management should be met, e.g., 
(i) the appointment of a highly skilled financial manager in the training division;

(ii) the delegation of greater financial authority to training managers which are linked to:

- performance agreements that create accountability for meeting specified training objectives;

- accurate and reliable systems for reporting and audit;

- a change in management culture so that managers at the different levels assume responsibility and accountability for the use of resources under their control to meet specific objectives;

(iii) the restructuring of the training division to allow for cost/profit centre accounting;

(iv) the creation of an effective budgeting process to generate realistic budgets based on projected activities and known costs rather than historical budgets;

(v) the discretion to apply virement between budget items to allow managers to adopt financial provisions to meet changing service needs;

(vi) the retention of a portion of the revenue generated to encourage income generation by the training division, bearing in mind that:

- the training division should retain a negotiated percentage of income generated by user fees;

- income accruing from the sale of training equipment or assets should be retained to a maximum negotiated amount between the training division and the department;

- in all other income generating schemes such as donations or the letting of vacant training space, the training division should retain a full 100 per cent of the income generated; and

(vii) the establishment of trading accounts implying that the training division manages the negotiated portion of revenue instead of returning it to the revenue account a department.

The requirements for effective financial management as listed above are of critical importance. The assigned public official is responsible for the effective and efficient utilization of public money and has to achieve value for money in meeting the objectives of the government in delivering of services to the public.

\section{CRITICAL ISSUES FOR CONSIDERATION}

The generation of additional income has moral implications. In this particular case, the is: Who really benefits from the generation of additional income and how does it facilitate the human development of the total population and the overall well-being of the people? 
In view of the above, Government should be cautious and be aware that its primary obligation is to all its people, and not to pursue the profit-making concept to such an extend that it affects society negatively. Therefore, the notion of generating additional income to facilitate a reduced tax burden through the application of some private sector concepts, while still delivering goods and services fairly and equitably, is indeed a complex one. However, this is a task that must be dealt with constructively and diligently, since both issues are important and relevant to the overall development of a nation. It is critical that government and other key role-players find a way to integrate these two different viewpoints in order to achieve a balance between them for sustainable growth. This delicate balance has to be maintained or the moral and ethical obligation to its people, especially the poor, will be undermined. It will also impact negatively on growth and development. Thus Government, in its effort to generate additional income, should always consider the short and long-term effects of their decisions and actions on society in general. This will allow Government to be ethically and morally conscious of every process - from policy formulation to policy implementation - to ensure that the needs of every community, rich or poor, are protected and development fairly and equitably distributed.

\section{CONCLUSION}

The government of the day fulfils an important role in the development of the skills of public officials. The acquiring of skills can be regarded as an important determinant of the delivery of services to people of South Africa. In order to develop and maintain skills of public servants, resources should be available. However, due to budget constraints the resources available to the training division in public departments are insufficient to cater for the training needs. This means that innovative ways of finding additional sources of funding for training should be found. Previous legislation such as the Exchequer Act of 1975, and the outdated Treasury Regulations did not allow for the generation of additional financial resources for departments.

The introduction of the Public Finance Management Act of 1999, paved the way for managers to be creative in the management of their departments. The new legislation allows for a department to generate additional income. The additional funds could then be used by for the training division to build and maintain the skills of public officials. However, it is important to avoid the misuse of the funds and a mechanism should be put in place to ensure effective utilisation of the resources. Appointing highly skilled financial managers, delegation of financial authority and the establishment of a departmental policy 
to ensure that the sources generated are earmarked for the training division could ensure that the funds will be utilized effectively.

\section{REFERENCES}

1 FRASER-MOLEKETI, G. (2000) Minister of Public Service and Administration. Budget Vote Speech, 13 April.

2 PRESIDENTIAL REVIEW COMMISSION (1998) "Developing a Culture of Good Governance", Report of the Presidential Review Commission on the Reform and Transformation of the Public Service in South Africa.

3 PURKIS, C. (2000) Project Administrator - Joint Universities Public Management Education Trust, 29 September, Interview.

4 REPUBLIC OF SOUTH AFRICA, DEPARTMENT OF FINANCE (2000) Budget Review.

5 REPUBLIC OF SOUTH AFRICA (2000) Department of Finance, National Expenditure Survey.

6 REPUBLIC OF SOUTH AFRICA (1999) Department of Public Service and Administration, Public Service Review Report, 1999/2000.

7 REPUBLIC OF SOUTH AFRICA (1999) South African Management Development Institute, Annual Report, 1999/2000.

8 REPUBLIC OF SOUTH AFRICA (2000) Treasury Regulations for Departments and Constitutional Institutions, Regulation Gazette no. 6822, 31 May.

9 REPUBLIC OF SOUTH AFRICA (1999) Public Finance Management Act, Act 1 of 1999, as amended by Act 29 of 1999.

10 REPUBLIC OF SOUTH AFRICA (1998) Department of Public Service and Administration, White Paper on Public Service Training and Education, 1998.

11 REPUBLIC OF SOUTH AFRICA (1997) Nonprofit Organisations Act, Act 71 of 1997.

12 REPUBLIC OF SOUTH AFRICA (1996) Department of Health, Hospital Strategy Report.

13 REPUBLIC OF SOUTH AFRICA (1995) Department of Public Service and Administration, White Paper on the Transformation of the Public Service.

14 REPUBLIC OF SOUTH AFRICA (1975) Exchequer Act, Act 66 of 1975.

15 VAN DER LINDE, G. (2000) Former Accountant-General, Department of State Expenditure, 29 September, Interview. 